\title{
Periodistas culturales y teatro en el EEES
}

\author{
Rosa María ArRÁEz BetANCORT \\ Universidad Europea Miguel de Cervantes \\ rarraez@uemc.es \\ Elvira JENSEN CASADO \\ Universidad Europea Miguel de Cervantes \\ mejensen@uemc.es \\ Carolina PAscual PÉRez \\ Universidad Europea Miguel de Cervantes \\ cpascual@uemc.es
}

Recibido: 22/10/2012

Aceptado: 23/01/2013

\begin{abstract}
Resumen
Ante la falta de estudios sobre la importancia de la literatura en la formación integral del periodista, este trabajo propone una metodología interdisciplinar entre periodistas y filólogos. El EEES permite aunar y potenciar también métodos activos en el aula que sirvan de guía, de manera específica, para el periodista cultural. Nos centramos en el teatro a partir de elementos esenciales caracterizadores como son: conflicto, estructura, lenguaje, otros códigos y puesta en escena. Y desde el periodismo cultural se aprovechan los conocimientos teatrales para insistir en la relevancia del mensaje periodístico cultural, tanto en forma como en contenido. El papel del periodismo cultural en la difusión del teatro y en la cultura es innegable. Palabras clave: teatro, periodismo cultural, métodos didácticos, EEES, metodología interdisciplinar
\end{abstract}

\section{Cultural Journalists and Drama in the EHEA}

\begin{abstract}
As there is very little research done on the importance of the literature in the academic training of the journalist, this paper proposes an interdisciplinary methodology between journalists and philologists. The EEES allows us to combine and strengthen active methods in the classroom that can be used as a specific guide for the cultural journalists. We focus on drama and our starting point are essential dramatic elements such as conflict, structure, language, other codes and scene setting. The cultural journalism takes advantage of the knowledge of drama in order to highlight the importance of the cultural journalists' message, not only in form but also in content. The role of the cultural journalist as drama and culture transmitter is undeniable.
\end{abstract}

Keywords: drama, cultural journalism, didactic methods, EEES, interdisciplinary methodology

\section{Referencia normalizada}

ARRÁEZ BETANCORT, Rosa María; JENSEN CASADO, Elvira; y PASCUAL PÉREZ, Carolina (2013): "Periodistas culturales y teatro en el EEES". Estudios sobre el Mensaje Periodístico. Vol. 19, Núm. especial marzo, págs.: 65-73. Madrid, Servicio de Publicaciones de la Universidad Complutense.

Sumario: 1. Introducción: el porqué de la literatura y el teatro para periodistas. 2. Metodología. 3. Desarrollo: periodistas teatrales y teatro en el EEES; 3.1. Periodistas culturales, literarios y teatrales; 3.2. Aspectos básicos para periodistas culturales que analicen una obra dramática; 3.3. Periodismo teatral en el EEES. 4. Conclusiones: cómo enseñar teatro a periodistas culturales en el EEES. 5. Referencias bibliográficas.

\section{Introducción: el porqué de la literatura y el teatro para periodistas}

La importancia de formar periodistas expertos en teatro que le otorguen mayor difusión como hecho cultural supone un reto al que se suma la escasa bibliografía en pe- 
riodismo cultural, literario y teatral. De todos modos, con nuestra aportación pretendemos enriquecer el periodismo teatral y no sólo mediante la crítica teatral propiamente a la que puede contribuir un periodista especializado sino también con el uso de otros géneros y formatos periodísticos. Serán las metodologías docentes recuperadas por el EEES las encargadas de facilitarnos la tarea.

En concreto, la lectura y estudio de la literatura y del teatro sirve a los estudiantes y profesionales del periodismo en general, y a los periodistas culturales en particular, para conocer y aplicar los recursos lingüísticos y expresivos del teatro en sus trabajos. Al establecer la relación entre la literatura y el periodismo, hemos de resaltar que ambos son el resultado de un proceso comunicativo con un emisor, periodista o escritor, que quiere transmitir un mensaje a un público. Martínez Fresneda (2011:102) insiste en que este acercamiento se sustenta "en la mirada previa que tanto periodista como escritor deben tener de la realidad" y en el lenguaje como elemento común de trabajo que marcará la percepción de la realidad de las audiencias.

Pero, si analizamos el proceso comunicativo al que se ven sometidos la literatura, en este caso el teatro, y el periodismo debemos aceptar algunas diferencias. La imagen de la realidad que perciben los públicos del periodismo y de la literatura es inevitablemente distinta en cuanto a los objetivos que persiguen sus emisores. Mientras en un texto literario serían fundamentalmente estéticos, en periodismo serían informativos, interpretativos y de opinión. No obstante, la selección e interpretación de unos datos informativos, así como la forma en que se presentan al público dependen de la visión concreta de la realidad que, consciente o inconscientemente, tengan los profesionales del periodismo.

Para Catalina Buezo (2011: 2), el estudio del texto literario debe realizarse a partir de un método comparatista filológico e histórico, con una metodología de investigación propia, que, desde nuestro punto de vista, el periodista cultural debe conocer y desarrollar para poder afrontar, en último término, la crítica teatral. De acuerdo con este planteamiento y con el objetivo de que el alumno tenga una doble visión, nos hemos planteado la enseñanza del teatro para periodistas a partir de la aportación interdisciplinar de periodistas y filólogos.

\section{Metodología}

Esta propuesta de enseñanza del teatro para profesionales y estudiantes de periodismo desde la aportación interdisciplinar de filólogos y periodistas está basada en la recopilación bibliográfica de materiales, su análisis y comparación en las siguientes áreas:

- Periodismo, periodismo especializado, cultural, literario y teatral

- literatura y teatro

- EEES y metodologías docentes.

Los escasos hallazgos en el abordaje del periodismo cultural, literario y teatral, así como las incursiones en las teorías propias del periodismo y del periodismo especializado, han permitido la elaboración de una definición de periodismo cultural y un perfil de este periodista, y también una contextualización de esta profesión y del término controvertido de cultura. 
Para determinar los conocimientos teatrales que estudiantes y profesionales deberían adquirir y aplicar en el desempeño de sus tareas, se ha elaborado una guía fruto de la revisión bibliográfica.

Finalmente, hemos procedido a aplicar las metodologías docentes recopiladas por el EEES para la adquisición de conocimientos y competencias sobre teatro y periodismo teatral, objetivos últimos de esta investigación.

\section{Desarrollo: periodistas teatrales y teatro en el EEES}

\subsection{Periodistas culturales, literarios y teatrales}

La enseñanza del teatro a periodistas culturales en el marco EEES requiere aclarar las labores de estos periodistas y el contexto que les rodea. Periodismo cultural equivaldría al ejercicio del periodismo sobre aquellos asuntos noticiables que se engloben dentro del controvertido y complejo término de cultura. En estas líneas nos ceñiremos a la cultura circunscrita a las artes (literatura y teatro) y no a la idea de cultura como un todo aunque el papel del periodismo en la difusión de la cultura resulta crucial en ambos planteamientos.

Los periodistas literarios han de adecuar mensajes especializados a audiencias más o menos especializadas, dependiendo del perfil del público. Contribuyen a la creación de cultura en una época de postmodernismo cultural que afecta también a la literatura y cuyas obras y autores parecen renegar de normas prestablecidas que traten de medir su calidad. Se denuncia la falta de complejidad y coherencia de las estructuras literarias, la carencia de ideas, de conflictos éticos, de racionalidad, etc. Además, marketing y publicidad posicionan una obra teatral y atraen a públicos masivos, resaltando lo anecdótico y frívolo. Parafraseando a Vargas Llosa (2012: 37), lejos de las pretensiones rupturistas y avanzadas de esta cultura, se propaga el conformismo dando al público una falsa impresión de culto, moderno... En la civilización del espectáculo, también Vargas Llosa (2012:37) alerta de la desaparición de la crítica cultural de los medios informativos a la que sólo se atiende si "se convierte también ella en diversión y espectáculo".

La complejidad del ejercicio periodístico cultural, literario y teatral queda sintetizada por Rodríguez Pastoriza (2006:16) cuando conviene que los profesionales del periodismo cultural deben transmitir "una postura crítica que vaya más allá de las meras definiciones". Este autor alude a la introducción en los mensajes periodísticos culturales de los problemas de la sociedad, a "saber interpretar la potencialidad crítica de los creadores y llevarla a sus receptores con todas sus consecuencias" y a "considerar la cultura como la producción de fenómenos que contribuyen a transformar el sistema social".

El periodista literario maneja los géneros periodísticos y los lenguajes más adecuados que le permitan llegar al público con eficacia y conoce el asunto sobre el que se especializa. Informan, explican, analizan, contextualizan, profundizan y opinan sobre aquellos hechos determinados como de interés informativo. Los factores que influyen habitualmente en la detección de una noticia no siempre encajan en los contenidos culturales. De ahí, por una parte, la dificultad para captar la atención de públicos masivos sobre cultura y teatro, y por otra, los esfuerzos posteriores del 
profesional por despertar su interés al incidir en la idea de la literatura y el teatro y su contexto. Se presupone, por parte del periodista, una cualificación periodística y una actitud responsable y honesta, en el modo de jerarquizar esta información cultural en cuanto a su grado de importancia en la sección o espacio en que se incluyen.

Para un periodismo al servicio de la difusión de la literatura, los profesionales disponen de tres géneros periodísticos básicos de información, interpretación y opinión con sus correspondientes subgéneros y que, dependiendo de los utilizados, requerirán una mayor o menor presencia del lenguaje literario. Con la intención de aclarar nuestra postura al respecto de lo que se entiende por periodismo literario o teatral, cabe recordar que diversos autores denominan como periodismo literario a un modo periodístico de contar basado en estrategias literarias, tales como Yanes Mesa (2004:108) o De Asís Garrote (2009:449-450), distinguiendo dos tipos de periodismo: el literario y el informativo. Por nuestra parte, hacer periodismo literario y teatral va más allá del uso del lenguaje, a favor de informar, interpretar y opinar sobre literatura y, en concreto, sobre teatro. En el periodismo, el lenguaje literario no puede imponerse hasta producir la desaparición de la intencionalidad periodística en favor del hecho literario y teatral, coincidiendo con León Gross (2010:119).

La aspiración de objetividad, y reconociendo la imposibilidad de lograrla, debe predominar sobre la idea de una subjetividad sin restricciones porque los públicos periodísticos requieren de información veraz analizada sobre literatura y teatro en periodismo de interpretación y de información veraz enjuiciada desde el periodismo de opinión. Las incursiones del lenguaje literario podrían realizarse en el caso de reportajes estéticos o entrevistas de personalidad, en la creación de ambiente en crónicas, $\mathrm{y}$, desde luego, en los géneros de opinión con la crítica teatral como baluarte. A pesar de la escasa presencia del teatro en los medios, debemos ser conscientes de que el periodismo transmite una idea de cultura, la crea y difunde. Y así lo hace con la literatura y el teatro, contribuyendo al desarrollo sociocultural.

\subsection{Aspectos básicos para periodistas culturales que analicen una obra dramática} Al enfrentarse al análisis y crítica de una obra teatral, habría que hacer una diferenciación básica entre lo que se considera un teatro convencional, el representado en sala, y el teatro representado en la calle. Debemos aclarar que en este artículo nos hemos centrado en el espectáculo teatral propiamente dicho, y no hemos tenido en cuenta por falta de espacio otros espectáculos.

Para establecer la diferencia entre el teatro de calle y el teatro convencional partamos de los elementos que constituyen el proceso de comunicación. Al hablar del emisor, en el teatro de calle podemos afirmar que son muchas las ocasiones en que se aglutina en una sola persona el papel de director, autor y actor. Es muy común que sea el mismo actor el que haya escrito o pensado el guión y no exista realmente un director como tal, sin embargo, en el teatro convencional el director de la representación, partiendo del guion dramático, mostrará sus intereses, creencias, críticas sociales y de valores, etc.

El actor, en apariencia un emisor, es realmente el canal del mensaje. Este actor, mientras que en el teatro en sala suele ser una persona formada, en el teatro de calle 
su preparación normalmente no es tan sólida como la del actor tradicional. Pero, aunque hablemos de un teatro de calle, el actor debe contar con una mínima formación que pasaría por un uso correcto de la voz, respiración, variación del tono y del volumen dependiendo del tipo de discurso, el control de la postura corporal, gestual, etc. Por otra parte, el público con el que cuenta el teatro de calle no se corresponde con el público del teatro de sala.

Otro aspecto diferenciador en estas dos variedades de teatro sería la importancia que se da al mensaje. Mientras que en el teatro en sala, tan importante es el texto dramático como la representación de éste en escena, hay que admitir que en el teatro de calle, se prescinde casi totalmente del texto y se prima la presentación, con lo que más que presenciar una obra teatral, nos encontramos, en muchas ocasiones, ante un espectáculo circense o un pasacalles, etc. En la transmisión del mensaje es importante analizar los códigos utilizados y en el teatro de calle se tiende a explotar los códigos no verbales como gesticulación, tono, voz, movimientos corporales, etc. que llegan incluso a sustituir cualquier sonido articulado, originando que se asocie al mimo, al circo, y se le considere un género menor. Junto con el código no verbal existen otros códigos como el vestuario, el decorado, la luz. Si hablamos de estos tres elementos tenemos que reconocer que existe una mayor calidad en el teatro en sala que en el de calle.

Pero qué elementos mínimos y esenciales hacen de una representación una obra teatral. En un texto teatral, el conflicto es el motor de lo dramático y los personajes se encuentran barreras y dificultades sobre el escenario tanto físicas como morales, sociales, familiares, etc. El enfrentamiento dará origen a la obra y a la vida de los personajes. Hay que recordar que la finalidad principal de la trama no es la acción por la acción, sino la evolución que ésta origina en los personajes. En todo conflicto teatral contamos con un personaje que representa una situación establecida, un antagonista, y un protagonista, que quiere cambiar esa situación por unas razones determinadas y urgentes. Este carácter de urgencia es un factor clave en toda obra teatral.

Las razones del cambio deben ser claras y concretas y nunca inverosímiles o generales ya que en tal caso la trama carecerá de interés y credibilidad. La motivación del personaje es su finalidad, es decir, para qué lo desea y por qué lo desea. Las motivaciones pueden ser más evidentes o más disfrazadas, como menciona Alonso de Santos (1998:110), pero son claves para que el personaje ejecute sus acciones. Si se desconoce el propósito y causa de las acciones de los personajes, lo que sucede en escena se verá como algo abierto y lejano y el público no conectará con la trama.

La estructura de una obra teatral responde a una serie de sucesos relacionados con una lógica y necesidad determinada, la trama de la historia, donde los personajes viven en un lugar (el espacio teatral) y en un tiempo (urgencia dramática), que da un sentido específico a todos los elementos que intervienen en la obra. Se introducen los antecedentes, la relación social, emocional y estados de ánimo de los personajes que nos ayudarán a entender el porqué del conflicto. El equilibrio inicial se romperá a partir de un incidente desencadenante que provoca una distorsión y tensión entre los personajes que despierta la curiosidad en el espectador por saber cómo se resolverá la trama y si el protagonista alcanzará o no su meta. El clímax nos marcará la acción principal del desenlace y fin de la historia. 
Aunque el código verbal no es el único código utilizado en el teatro es el medio más poderoso para transmitir el mensaje dramático y el conflicto, como apunta Spang (1998: 110). El lenguaje en el teatro es la herramienta más directa que tienen los personajes de conseguir algo de otro. Un buen diálogo debe tener una dimensión poética y no debe caer en la trivialidad, debe ser verosímil y emocional a la vez. El código verbal dentro del texto teatral, por tanto, se corresponde fundamentalmente con los discursos de los actores, donde se reflejan las incertidumbres y preocupaciones del personaje principal. En estos discursos es importante fijarse en la información que aportan, tal y como indican Wallis y Shepherd (2002:42) así como en las distintas funciones que aportan al texto dramático.

Dentro del código verbal también se encuentran los silencios, más extensos que las pausas. El hecho de que no haya lenguaje no implica que no haya mensaje. Pero el teatro no debe solamente echar mano del código verbal ya que el espectador de una representación teatral recibe óptica y acústicamente una serie de informaciones simultáneas. Siguiendo a Spang (1991: 206) se puede decir que esencialmente hay tres tipos de decorados: el neutro, invariable y carente de elementos que nos ubiquen en un lugar preciso; el estilizado que presenta un mayor detalle del espacio de la historia sin llegar a reproducirlo fiel y perfectamente como ocurre en el decorado realista o naturalista. Otros elementos importantes en una representación teatral son la iluminación, que permite ver lo que ocurre en el escenario, así como representar el paso del tiempo, estaciones, incluso estados de ánimo, etc.; o el sonido y sus efectos especiales que contribuyen a la creación de diferentes ambientes. Otros códigos extraverbales que ayudan a la caracterización son la estatura, los gestos, el maquillaje, peinado, indumentaria, etc.

Como menciona Ariel Rivera (1993: 79), el teatro cumple con diferentes funciones: expone conflictos, contrapone valores, enseña, divierte, sublima, denuncia, critica o remueve el inconsciente, pero como arte su propósito debe ser llevar al espectador a tomar conciencia de su realidad y a involucrarlo en los errores y aciertos en que incurre el hombre.

\subsection{Periodismo teatral en el EEES}

El EEES propicia un contexto favorecedor para una metodología interdisciplinar entre periodistas y filólogos que tratan de formar futuros periodistas culturales, literarios y, en nuestro caso, teatrales. Se trata de lograr una visión global que les permita interrelacionar los conocimientos adquiridos en la universidad con sus tareas profesionales y de que estén capacitados para informar con responsabilidad, autonomía, independencia, la mayor objetividad posible, espíritu crítico y ética profesional.

Todo ello a partir de una metodología que siguiendo a Mario de Miguel Díaz (2005:35), aluden a las decisiones sobre qué y cómo enseñar, a su justificación, a los recursos didácticos necesarios para las acciones secuenciadas, al logro de los objetivos pretendidos y al desarrollo de las competencias estipuladas.

Dadas las implicaciones e influencia del periodismo y del periodismo cultural en líneas anteriores, los alumnos de periodismo deben adquirir, además de competencias genéricas comunes, unas competencias específicas como la capacidad y habilidad para 
buscar, seleccionar y organizar cualquier tipo de fuente o documento de utilidad para la elaboración o creación de contenidos, capacidad para el análisis crítico de la influencia de los medios de comunicación en la sociedad, para conocer y aplicar el método periodístico, para valorar el hecho noticiable y comunicarlo en el lenguaje y a través de los géneros periodísticos, y capacidad para la lectura y análisis de textos periodísticos, principalmente. Con respecto a los resultados de aprendizaje, el alumno será capaz, entre otros, de emitir razonadamente juicios, críticas e ideas creativas, de desarrollar interés por el conocimiento de otras realidades culturales literarias contemporáneas y de seleccionar y tratar correctamente con las fuentes informativas. También, será capaz de analizar, comparar y elaborar géneros periodísticos informativos, interpretativos y de opinión en distintos soportes, etc.

De los distintos tipos de métodos didácticos, siguiendo a de Miguel Díaz (2005:37), apostamos por el predominio del seminario en combinación con la lección tradicional, método de caso, grupo pequeño de trabajo, metodología de aprendizaje cooperativo y resolución de problemas. Específicamente, la planificación de la enseñanza del periodismo teatral supondría el desarrollo de estas metodologías docentes siempre vinculadas a las competencias y resultados de aprendizaje ya expuestos.

\section{Conclusiones: cómo enseñar teatro a periodistas culturales en el EEES}

Partiendo de la lección tradicional sobre los elementos de análisis de la obra teatral, integraremos a los estudiantes en grupos pequeños de trabajo. Sirva de ejemplo, en nuestro caso, el Festival Internacional de Teatro y Arte de Calle (TAC) de Valladolid para el aprendizaje in situ de las características de este teatro. Podría aprovecharse alguna temática del teatro de calle y contrastarla con el teatro convencional para ver las diferencias en el texto dramático, presentación, conflictos y uso de códigos entre ambos. También en estos grupos pequeños introduciremos el método de caso y de resolución de problemas con ejercicios prácticos secuenciados donde los estudiantes accedan a los directores, actores u organizadores del evento realizando entrevistas y reportajes que plasmarán en diferentes soportes. Estas prácticas culminarían con la realización de críticas teatrales de diferentes representaciones.

Aplicando también el método de aprendizaje cooperativo en el que predomina la interacción entre compañeros como "fuente de conocimiento", según Monereo y Pozo (2003:27-28), organizaremos discusiones grupales acerca de las diferencias en el uso de códigos teatrales y de los enfoques posibles en la elaboración de un mismo género periodístico. Estas discusiones estarán basadas en lecturas previas sobre fragmentos de obras teatrales y géneros periodísticos ya publicados sobre la cuestión que nos ocupa. La reflexión y conexión con otros asuntos relacionados que demanda el método de aprendizaje cooperativo se concretaría en la valoración de las obras, su repercusión en prensa y su relación con el momento sociocultural actual. El análisis y estudio efectuado por los alumnos de obras de mayor o menor calidad y del posicionamiento de la crítica publicada sobre el teatro de calle, les permitirá tener una visión crítica del fenómeno en cuestión. Como método didáctico aglutinador de las prácticas anteriores, se llevará a cabo un seminario en el que se organizarán diferentes mesas redondas que permitirán conjugar las aportaciones de los profesionales del teatro, directores, 
actores y críticos teatrales con las propias apreciaciones y conclusiones a las que han llegado los alumnos. De este modo, se cumpliría la función del seminario al facilitarse la interacción entre práctica y teoría logrando que el alumno profundice en los contenidos propuestos para su formación en periodismo teatral.

Creemos que estos métodos expuestos permitirán el desarrollo de competencias y la consecución de resultados de aprendizaje previstos. Como propone Isabel Solé (2003:212), debemos de reflexionar sobre: "qué queremos que sepan, sepan hacer y sean los futuros profesionales" y lograrlo depende de la interdisciplinariedad docente. En el caso propuesto queda fuera de dudas porque periodismo cultural y teatro se complementan. El periodismo cultural contribuye a la difusión del teatro y de la cultura y al mismo tiempo el saber de teatro y conocer los géneros y lenguajes periodísticos más adecuados conforman el perfil del periodista especializado en cultura.

\section{Referencias bibliográficas}

ALONSO DE SANTOS, José Luis (1998): La escritura dramática. Madrid, Castalia.

ARIEL RIVERA, Virgilio (1993): La composición dramática. México, Gaceta.

ASÍS GARROTE, María Dolores de (2009): "Periodismo y literatura en la segunda mitad del siglo XX", en PALOMO, María del Pilar (ed.): Movimientos literarios y periodismo en España. Madrid, Síntesis.

BUEZO, Catalina (2011): "De la escritura, los medios de comunicación y otras razones de la literatura" Revista Espéculo, no 21, www.ucm.es/info/especulo/numero21/c_buezo.html [fecha de consulta: 04/04/2011]

LEÓN GROSS, Teodoro (2010): "La retórica del articulismo periodístico-literario", en RODRÍGUEZ RODRÍGUEZ, Jorge Miguel y ANGULO EGEA, María (coord.): Periodismo literario. Naturaleza, antecedentes, paradigmas y perspectivas. Madrid, Fragua.

MARTÍNEZ-FRESNEDA, Humberto (2011): "La comunicación, base de toda creación periodística literaria", en BLANCO, Ignacio y FERNÁNDEZ, Pilar. (coord.): Entre la ficción y la realidad. Perspectivas sobre periodismo y literatura. Madrid, Fragua, pp. 102-111.

MIGUEL DÍAZ, Mario de (dir., 2005): Modalidades de enseñanza en el desarrollo de competencias. Oviedo, Ediciones Universidad de Oviedo.

MONEREO, Carlos y POZO, Juan Ignacio (2003): "La cultura educativa en la universidad: Nuevos retos para profesores y alumnos" en MONEREO, Carlos y POZO, Juan Ignacio (eds): La universidad ante la nueva cultura educativa. Enseñar y aprender para la autonomía. Madrid, Síntesis.

RODRÍGUEZ PASTORIZA, Francisco (2006): Periodismo cultural. Madrid, Síntesis.

SOLÉ, Isabel (2003): "Conclusiones: el profesor universitario en el siglo XXI", en MONEREO, Carlos y POZO, Juan Ignacio. (eds): La universidad ante la nueva cultura educativa. Enseñar y aprender para la autonomía. Madrid, Síntesis. 
SPANG, Kurt (1991): Teoría del Drama. Lectura y análisis de la obra teatral. Pamplona, Eunsa.

VARGAS LLOSA, Mario (2012): La civilización del espectáculo. Madrid, Alfaguara.

WALLIS, Mick Y SHEPHERD, Simon (2002): Studying Plays. London, Oxford University Press.

YANES MESA, Rafael (2004): Géneros periodísticos y géneros anexos. Una propuesta metodológica para el estudio de los textos publicados en prensa. Madrid, Fragua.

\section{Dra. Rosa María ARRÁEZ BETANCORT}

Universidad Europea Miguel de Cervantes (Valladolid)

rarraez@uemc.es

Profesora Adjunta

\section{Dra. Elvira JENSEN CASADO}

Universidad Europea Miguel de Cervantes (Valladolid)

mejensen@uemc.es

Profesora Adjunta

\section{Lda. Carolina PASCUAL PÉREZ}

Universidad Europea Miguel de Cervantes (Valladolid)

cpascual@uemc.es

Profesora Adjunta 